\title{
An analysis of the socio- demographic characteristics of sole registered births and infant deaths
}

\author{
Julie Messer Office for National Statistics
}

\section{Abstract}

\section{Background}

Differences in birth characteristics and infant mortality rates by marital status and birth registration type reflect complex underlying factors. In particular, births registered solely by the mother are seen as a disadvantaged group. This article analyses the socio-demographic characteristics of births by registration type and parents' marital status and explores these differences for health outcomes.

\section{Methods}

Birth notifications data from the NHS Numbers for Babies system was linked to birth registration data held by the Office for National Statistics (ONS) for births occurring in 2007 and 2008 in England and Wales. This dataset was further linked to death registration data to identify infants who died before their first birthday.

Regression analysis was used to compare factors and health outcomes across marital and registration status groups. Regression models were calculated to determine the main risk factors for poor outcomes.

\section{Results}

The registration groups differed in the age of the mother at birth, the proportion of young mothers, ethnic group distribution and measures of deprived circumstances. The joint registered-different address and sole registered groups were similar in the proportion of young mothers and the deprivation indices. The groups also differed in the proportion of low birthweight and premature babies. The joint registered-different address and sole registered groups both had higher percentages of 'small for gestational age' babies compared with the within-marriage and joint registered-same address groups. The stillbirth rate was highest in the sole registered group. Both the joint registered-different address and sole registered groups had higher infant mortality rates compared with the withinmarriage and joint registered-same address groups. Multivariate analysis indicated that low birthweight was a key factor in infant mortality. 


\section{Conclusions}

Births registered solely by the mother were found to be a disadvantaged group but were also similar to the joint-registered group living at different addresses in their main sociodemographic characteristics and health outcomes. The joint-registered group living at the same address was similar to the within-marriage group across the same measures. This argues that, in the 21st century, the distinction between infants with 'resident' and 'nonresident' fathers is more meaningful for health outcomes than that between births inside and outside marriage. 


\section{Contents}

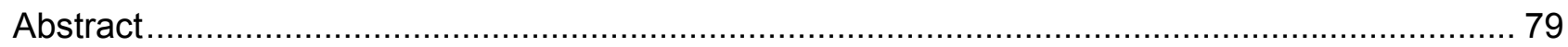

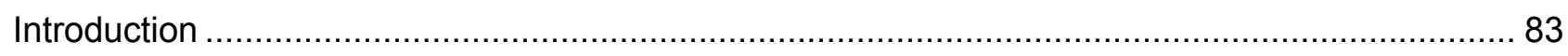

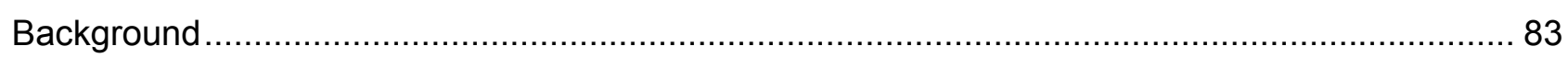

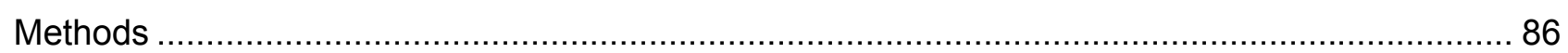

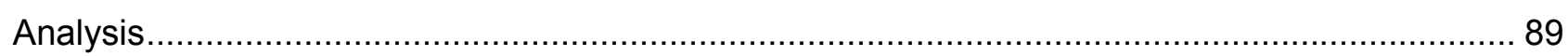

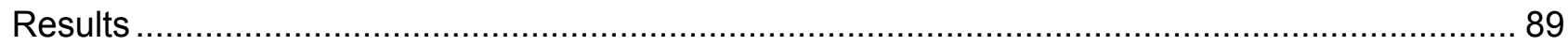

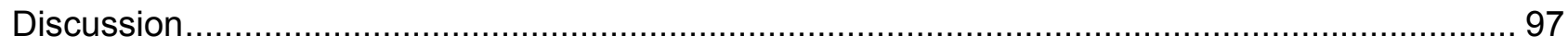

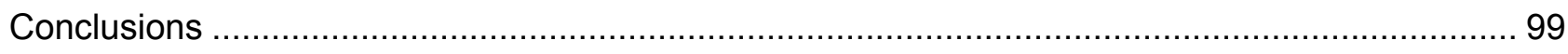

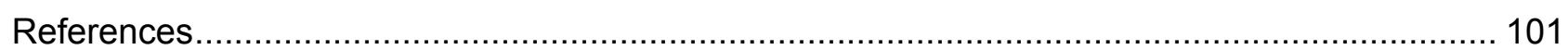

\section{List of Figures}

Figure $1 \quad$ Live births by marital status / registration status type, 1993-2009 ...................... 84

Figure 2 Infant mortality rates by marital status / registration type, 1993-2008................. 86 


\section{List of Tables}

Table 1 Socio-demographics characteristics for marital status/registration type groups, babies born in 2007-08

Table 2 Health characteristics and mortality outcomes for marital status/registration type groups, babies born in 2007-08

Table 3 Infant mortality by ONS cause groups and registration type, babies born in 2007-08

Table 4a Unadjusted and adjusted odds ratios (OR) for low birthweight by registration group, singleton births

Table 4b Unadjusted and adjusted odds ratios (OR) for low birthweight by registration group, singleton births.

Table 5a Unadjusted and adjusted odds ratios (OR) for infant mortality by registration group, singleton births.

Table 5b Unadjusted and adjusted odds ratios (OR) for infant mortality by registration group, singleton births.

Table A1a Variables included in the analyses for low birthweight .................................... 104

Table A1b Variables included in the analyses for infant death ......................................... 104

Table B1 Unadjusted and adjusted odds ratios (OR) for low birthweight by registration group,

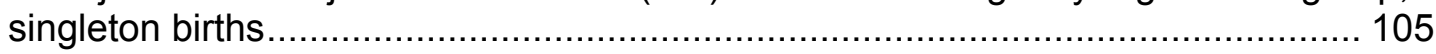

Table B2 Unadjusted and adjusted odds ratios (OR) for low birthweight by registration group, singleton births..... 106

Table $\mathrm{C} 1$ Unadjusted and adjusted odds ratios (OR) for infant deaths by registration group, singleton births. 


\section{Introduction}

The changing pattern of marriage and household structure in England and Wales in recent decades has lead to an increase in the proportion of births occurring outside marriage (Office for National Statistics, 2010a). There is evidence that good maternal health and healthy pregnancies and babies are more likely within marriage. In particular, births registered solely by the mother, generally considered to be lone parents, are considered disadvantaged (Smallwood, 2004). This article describes some key socio-demographic characteristics of births occurring in England and Wales in 2007 and 2008 across their marital status and registration type groupings. These are related to a range of health outcomes associated with both the pregnancy and the baby to determine differences across registration groups in 2011.

\section{Box 1 Marital status/ registration type for births}

\author{
Registration group \\ Within-marriage \\ Joint-same \\ Joint-different† \\ Sole registered
}

Term used in this article

\section{Definition}

marital status / registration type group

within marriage

registered jointly by both parents living at the same address registered jointly by both parents living at different addresses registered solely by the mother

† father must be present at registration or provide details by statutory declaration

\section{Background}

In England and Wales, registration of a birth is legally required and the marital status of the parents can be determined from information collected by the registrar (see Box 1). In the last fifty years, the number of live births registered outside marriage has increased sevenfold with 46 per cent of live births registered outside marriage in 2009 (Figure 1) (Office for National Statistics, Series DH3, 2010). Outside of marriage, the father can be recorded on the birth certificate if he is present at the registration or by statutory declaration. Since 1983, this joint registration group has distinguished parents living at the same address (generally considered a cohabitation) or those living at different addresses. About seven per cent of live births are registered solely by the mother, a proportion that has remained fairly constant. However, the composition of this group has changed over time from predominantly widows to never married young mothers (Berthoud, McKay and Rowlingson, 2004). This is now generally considered to represent a group of lone mothers who are raising their children with more disadvantages than the other registration groups. 


\section{Figure $1 \quad$ Live births by marital status / registration status type, 1993-2009}

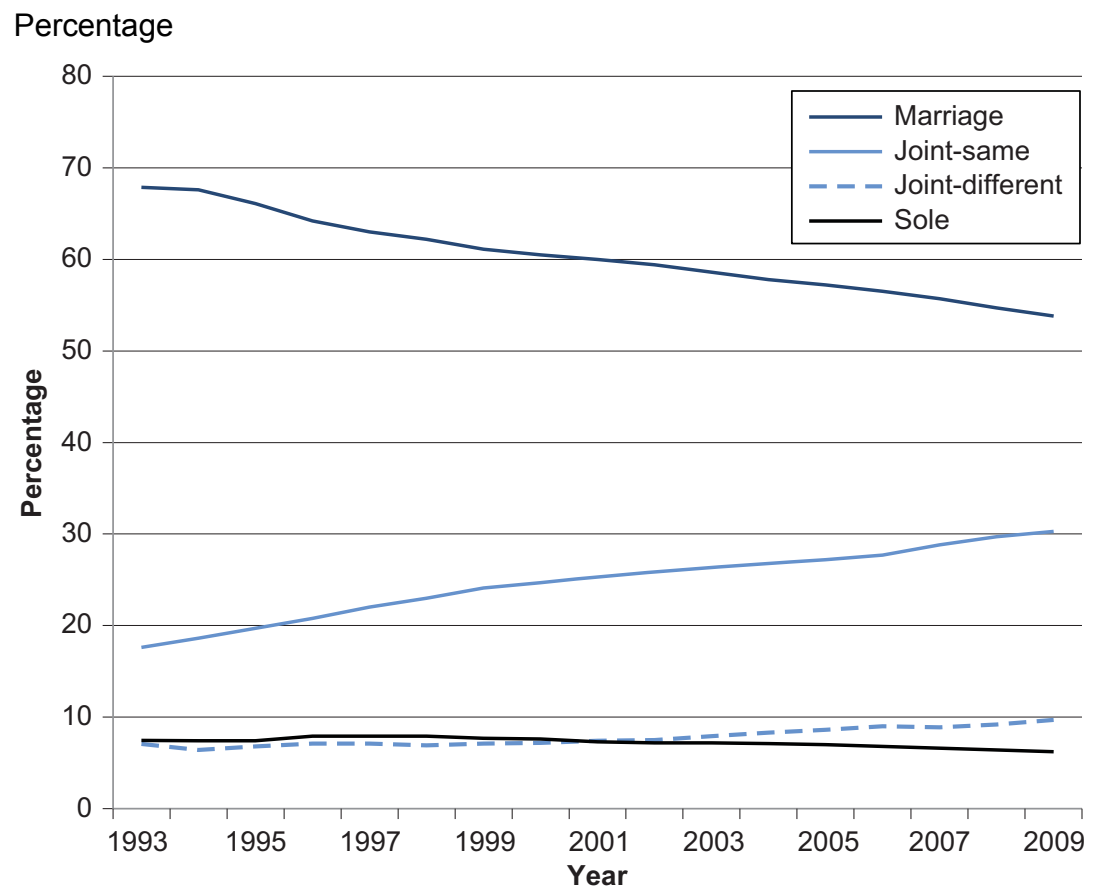

Source: ONS

Findings from the General Lifestyle Survey show that seven per cent of households in Great Britain are lone parent households with dependent children, including widowed, divorced, separated or single parents (Shouls et al, 1999). It is uncertain what proportion of sole registered births are raised in lone parent households or what proportion are living in other circumstances, such as the mother remaining in her parental home. There is limited information on the characteristics of mothers who register the birth of their babies alone. However, using data from the ONS Longitudinal Study, such mothers were shown to be, on average, four years younger at the birth of their first child compared to all other mothers (Smallwood, 2004). This sample of women, born between 1955 and 1962, were less likely to come from a non-manual background compared to all mothers in the study. This was based on their own father's social class (assessed in 1971) so this group may be less representative of women registering a birth alone in the 21 st century.

Further, Smallwood (2004) reported that women registering a birth alone were more likely to have had an absent father when growing up. The link between absent fathers and young, lone pregnancies has been well documented although whether the mechanism of this intergenerational pattern works through biological means (girls without fathers start first menstruation at younger ages: Moffitt et al, 1992), or through parenting or other mechanisms associated with deprivation (Wellings and Wadsworth, 2004) is not clear. Also, associations with non-resident fathers may vary: recent data from the Millennium Cohort Study indicated that in about a third of sole registered births, the mother reported close contact with the father (Kiernan \& Smith, 2003; Smallwood, 2004). An eight-year follow-up of mothers who solely registered the birth of their baby in 1988 showed that fewer of them married within this period than for those who had jointly registered the birth (Haskey, 1999), suggesting less involved fathers. In recent years there have been attempts to change legislation to increase the number of birth registrations which hold details of the father 
(Department for Work and Pensions, 2008). The aim is to promote child welfare and parental responsibility through increasing the involvement of fathers.

Improving maternal physical and mental health is recognised as one strategy for improving outcomes in childhood (Department of Health, 2010a). However, past surveys of households (1979-1995) have reported a range of disadvantages for lone mothers, including poorer selfperceived general health and more reported acute and chronic illness (Shouls et al, 1999). The health of the mother is vital to a healthy pregnancy as are her health behaviours such as smoking and drinking during the pregnancy, physical activity and maternal weight and breastfeeding (Department of Health, 2010a).

Early markers of the baby's health include low birthweight (less than 2,500 grams), prematurity (born before 37 completed weeks gestation) and being small for gestational age. Such babies are more prone to poor health outcomes, including dying before their first birthday (Perry and Lumey, 2004), living with respiratory disease (Strachan and Sheikh, 2004), and being at increased risk for coronary heart disease in mid-life (Lawlor, Ben-Schlomo and Leon, 2004). A range of characteristics are associated with low birthweight such as the mother's young age at baby's birth, mother's ethnicity, and being born outside marriage (Collingwood Bakeo, 2004). Further, babies with low birthweight are significantly more likely in the sole registered group when compared with the within-marriage and joint-registered groups combined (Dibben, Sigala and Macfarlane, 2006). There is also evidence that low birthweight is more prevalent in deprived areas (Kuh and BenSchlomo, 2004). There may be an interaction between mother's age at the birth of their baby and area income deprivation, with adverse effects on birthweight from area deprivation strongest for older mothers, although young mothers remain at high risk for low birthweight babies (Dibben, Sigala and Macfarlane, 2006).

Infant mortality is seen as a key measure among health outcomes. Further, there is a long established link between health inequalities and infant mortality, with most causes of infant death showing a socio-economic gradient (Oakley et al, 2009). A previous Department of Health Public Service Agreement (PSA) target measured health inequalities by comparing the infant mortality rate for families with fathers in routine and manual occupations with the overall infant mortality rate for families with fathers (that is, within-marriage and joint-registered births). Over time, the rate of infant mortality declined but there was little overall reduction in the gap between these groups (Department of Health, 2010b). This measure excluded the sole registered group, where father's NS-SEC was not collected. However, the infant mortality rate in the sole registered group has been consistently one of the highest of the registration groups (Figure 2).

Income also distinguishes health inequalities and lone parent families are particularly likely to be in poverty (Department of Health, 2010a). The White Paper 'Healthy Lives, Healthy People' emphasised reducing child poverty and improving the health of the poor fastest, and recognised that action taken early in development (including prenatally) is the most effective. 


\section{Figure 2 Infant mortality rates by marital status / registration type,} 1993-2008

Infant mortality rates by marital status/ registration type, 1993-2008

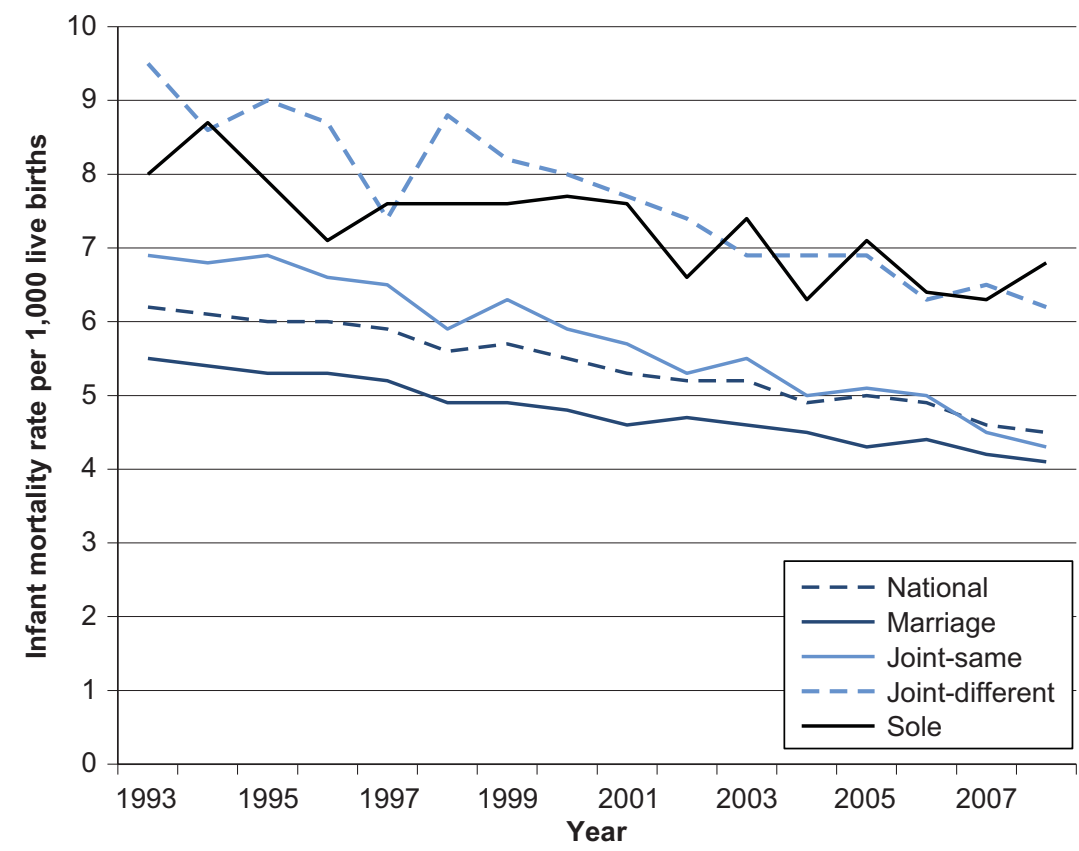

Source: ONS

Using data for births occurring in 2007 and 2008, this article aims to explore the sociodemographic characteristics of the registration groups, with particular attention to the sole registered group. A range of health outcomes in relation to birth (low birthweight, prematurity, and small for gestational age) and death (stillbirth, neonatal and infant mortality rates and cause of death) will be explored by registration group. Multivariate analysis of these factors will determine which characteristics, including maternal age, baby's ethnicity and area deprivation, explain any differences in health outcomes across registration group.

\section{Methods}

The analysis presented here is based on the linkage of two main data sources: ONS birth and death registration data, and birth notifications data from the NHS Numbers for Babies programme.

\section{ONS birth and death registration data}

Registration of a birth within England and Wales is legally required within 42 days of its occurrence. As well as details of the birth (date of birth, sex, single or multiple birth) additional information is collected about the parent both for the public register and for statistical purposes, such as mother's usual residence and her date of birth. Information is collected about the father if they are married or if the father is present (joint registration). Marital status and registration type is determined from birth registration records.

Stillbirths are also registered on a single certificate which records similar information as well as birthweight, gestational age and information regarding the cause of death. A stillbirth is where a 
baby was born after 24 or more weeks completed gestation and did not, at any time, breathe or show other signs of life. Rates for stillbirths are reported per 1,000 total births (live and stillbirths).

Registration data on all deaths occurring in England and Wales are held by ONS. Routine linkage of birth records to the death registration records determines those babies who died before their first birthday. Neonatal deaths are those which occur under 28 days following a live birth. Postneonatal deaths are those occurring between 28 days and one year. Together they comprise infant deaths. Neonatal and infant mortality rates are reported per 1,000 live births.

\section{Birth notifications (NN4B) data}

The NHS Numbers for Babies (NN4B) electronic system for the notification of each birth allocates NHS numbers and documents key birth details not collected at birth registration. The birth must be notified to the Regional Director of Public Health within 36 hours of its occurrence by the hospital where the birth took place, or by the midwife or doctor in attendance at the birth. Birthweight is automatically linked to all birth registration records. Since 2005, ONS has linked more variables from the birth notification data to the birth registration records (see Hilder et al, 2007). This permits an analysis of births and infant deaths by these additional variables.

The baby's ethnic group as defined by the mother is collected on the birth notifications system. For this analysis this has been placed into broad groups: Asian (Bangladeshi, Indian, Pakistani and any other Asian background); Black (African, Caribbean and any other Black background); White (White British, White Irish and any other White background) and All others (Chinese, all mixed groups and any other ethnic group). About 9 per cent of records have 'Not stated' ethnicity.

Gestational age in completed weeks is recorded for all live births. Babies born before 37 completed weeks are considered pre-term.

\section{Small for gestational age (SGA)}

Low birthweight and prematurity are both measures of fetal development. A further measure of fetal development is being small for gestational age (SGA), which describes babies whose birthweight lies below the 10th percentile for that gestational age. Not all babies who are SGA have a pathological growth restriction but may be constitutionally small. This may explain why babies of Bangladeshi, Indian or Pakistan origin are more likely to be SGA than White British babies (Office for National Statistics, 2010b). Babies from multiple births are prone to being SGA due to additional demands on the placenta. This same report on 2007 and 2008 births showed that babies from multiple births were more than twice as likely to be SGA than singletons (20.7 per cent versus 9.4 per cent). However, a range of environmental and maternal factors also contribute to SGA.

\section{Measures of deprivation}

The Index of Multiple Deprivation (IMD) 2007 assesses deprivation across seven domains at a small area level for England (Communities and Local Government, 2007). The indices were applied in quintiles at the Lower Super Output Area (LSOA) level using the postcode of the mother's usual residence. The Health Deprivation and Disability domain does not include direct measures of birth characteristics or infant mortality but may still produce over-estimated associations between deprivation and health (see Gartner et al, 2008). 
The Index of Multiple Deprivation for Wales (WIMD) 2008 is based on slightly different measures across eight domains at a small area level (Welsh Assembly Government, 2008) (see Box 2). The indices were applied in the same way, that is, in quintiles at the Lower Super Output Area (LSOA) level using the postcode of the mother's usual residence. The Health domain does include low birthweight as one of its indices suggesting a possible influence on the findings although in general there is little evidence for over-estimated associations (Gartner et al, 2008).

Both measures of deprivation involve assigning a deprivation score and a rank to each area which can be grouped into quintiles. The percentage of mothers residing in the most deprived quintile is reported for England and Wales separately.

\section{Box 2 Measures of deprivation}

\begin{tabular}{|c|c|c|c|}
\hline \multicolumn{3}{|c|}{ IMD 2007 England } & $\underline{\text { WIMD } 2008 \text { Wales }}$ \\
\hline Income & \multicolumn{3}{|c|}{ Income } \\
\hline Employment & \multicolumn{3}{|c|}{ Employment } \\
\hline \multicolumn{3}{|c|}{ Health and Disability } & Health \\
\hline \multicolumn{3}{|c|}{ Education, Skills \& Training } & Education \\
\hline \multicolumn{2}{|c|}{ Barriers to Housing } & Housing & \\
\hline Crime Crin & & & and Fire \\
\hline Living Environ & ent & Environmen & $\mathrm{t}$ \\
\hline
\end{tabular}

\section{Cause of death}

In 1986 England and Wales introduced a special certificate for neonatal deaths following the recommendations of the World Health Organisation (WHO, 1977). The certificate is designed to collect information about the mother and the baby in order to determine the earliest cause in the chain of events that led to the death of the baby. While this certificate permits more flexibility for those completing the certificates it is not possible to derive an underlying cause directly from the information recorded. Thus, ONS devised a hierarchical classification system (Dattani and Rowan, 2002) to identify a single underlying mechanism based on the Wigglesworth classification (Wigglesworth, 1980). The cause groups are organized around the likely timing of the condition or damage leading to the death in relation to birth: before, during or after. This classification system can also be applied to postneonatal deaths to enable direct comparison of neonatal and postneonatal deaths and the reporting of cause of death for infants. 


\section{Analysis}

The registration groups were compared across socio-demographic characteristics and health outcomes using logistic regression analysis. All registration groups were compared to the withinmarriage group, with post-estimation comparisons of the other groups. For two main health outcomes - low birthweight and infant mortality - the size of effect is reported as odds ratios with $95 \%$ confidence intervals. This is reported in two ways: unadjusted odds ratios and adjusted for potential explanatory variables. Details of the models and the variables' order of entry into the regression analysis are detailed in Annex A. The percentage of the difference explained by the addition of the explanatory variables is also reported. All analyses were carried out in Stata version 9.2 SE (StataCorp, 2007).

\section{Results}

This analysis is based on the 1.4 million births occurring in $2007(689,120)$ and $2008(708,253)$ which were successfully linked to their birth notifications records. This represents 99.9 per cent of live births from the registration records. This was further linked to death registration records giving a total of 6,448 infant deaths, 3,254 in 2007 and 3,194 in 2008. 
Socio-demographic characteristics

Table 1 Socio-demographics characteristics for marital status/registration type groups, babies born in 2007-08

England and Wales

Mean/ Per cent

\begin{tabular}{cccc}
\hline All & Marital status/type of registration & \\
\hline & Inside marriage & Joint registration & Sole registration \\
& & same address & different address
\end{tabular}

Live births

$\begin{array}{lrrrrr}\text { All } & 1,397,372 & 771,780 & 408,149 & 126,408 & 91,035 \\ \% & & 55.2 & 29.2 & 9.1 & 6.5\end{array}$

Age of mother

Mean age mother (years)

Per cent under 20 years

6.4

\section{Baby characteristics}

Per cent multiple births

\section{Ethnicity}

White

Asian, Asian British

All Others

\section{Deprivation}

Per cent Quintile 5 IMD2007

1 Of those with known ethnicity.

All differences were statistically significant at the $p<0.001$ level except for two comparisons which were not significant. Multiple births: joint-same and sole registered. WIMD: joint-different and sole registered

Source: ONS 
Just over half of the live births were registered within marriage and almost a third were registered jointly by parents living at the same address, indicating that the majority of births ( 85 per cent) were registered in households which may be characterised as having resident fathers. Less than seven per cent of live births were registered solely by the mother (Table 1) and together with births registered jointly by parents living at different addresses, this indicates that 15 per cent of births were registered to households which may be characterised as having non-resident fathers.

Mothers in the sole registered group were younger than married mothers, but were similar to mothers in the joint-different group, with both having more than 20 per cent aged under 20 years (compared to less than 1 per cent within-marriage and 8 per cent in the joint-different group). Babies born to older mothers (aged 35 years and over) were more common in the within-marriage group compared to all other registration groups $(p<0.001)$. The joint-different group had fewer older mothers than the sole registered $(p=0.05)$ and joint-same $(p<0.01)$ groups.

Most multiple live births occurred within marriage. The difference in percentage of multiple births in the joint-same and sole registered groups was not statistically significant.

Ethnic groups were not equally represented across the registration groups. White births were particularly represented in the joint-same group but all registration groups differed in the proportion of non-white births. However, the composition of these non-white births were different across some groups: Asian births were most likely to occur within marriage while Black births were most likely to be registered solely by the mother and also were similarly represented in the joint-different group.

The sole registered group were twice as likely to live in deprived circumstances, represented by the IMD or WIMD score, compared to the within-marriage group, as were the joint-different group. This was true whether they lived in England or Wales, but for Wales, the joint-different and sole registered groups did not differ from each other. The joint-same group was somewhat more deprived than the within-marriage group.

All the reported differences between groups were statistically significant at the $p<0.001$ level except where stated above. 


\section{Health outcomes}

\section{Table $2 \quad$ Health characteristics and mortality outcomes for marital status/registration type groups, babies born in 2007-08}

England and Wales

Per cent/ Rates

\begin{tabular}{|c|c|c|c|c|c|}
\hline & \multirow[t]{3}{*}{ All } & \multicolumn{3}{|c|}{ Marital status/type of registration } & \multirow{3}{*}{ Sole registration } \\
\hline & & Inside marriage & Joint regist & ation & \\
\hline & & & same address & different address & \\
\hline $\begin{array}{l}\text { Health Characteristics for } \\
\text { singleton births }\end{array}$ & & & & & Per cent \\
\hline Per cent low Birthweight & 5.7 & 5.0 & 5.7 & 7.9 & 8.6 \\
\hline $\begin{array}{l}\text { Per cent under } 37 \text { weeks } \\
\text { gestational age }{ }^{1}\end{array}$ & 5.9 & 5.3 & 5.9 & 7.6 & 8.0 \\
\hline $\begin{array}{l}\text { Per cent Small for Gestational } \\
\text { Age }(S G A)^{2}\end{array}$ & 9.4 & 8.6 & 9.3 & 11.9 & 13.2 \\
\hline Mortality Outcomes & & & & & Rates \\
\hline $\begin{array}{l}\text { Stillbirth rate per } 1,000 \text { total } \\
\text { births }\end{array}$ & 5.1 & 4.8 & 5.2 & 5.2 & 6.6 \\
\hline $\begin{array}{l}\text { Neonatal mortality rates per } \\
1,000 \text { live births }\end{array}$ & 3.2 & 2.9 & 3.2 & 4.2 & 3.7 \\
\hline $\begin{array}{l}\text { Infant mortality rates per } 1,000 \\
\text { live births }\end{array}$ & 4.6 & 4.2 & 4.5 & 6.4 & 6.3 \\
\hline
\end{tabular}

1 Of those with known gestational age

2 SGA: birthweight below 10 th percentile for each gestational age

Source: ONS

Babies from multiple births have lower birthweight on average than singleton babies, largely due to the fact that multiple births rarely go to term. Therefore, the comparison of registration groups for low birthweight, prematurity and small for gestational age was carried out for singleton births only. The joint-different and sole registered groups had higher proportions of low birthweight babies, preterm babies and small for gestational age (SGA) babies than all other groups. All groups differed significantly at the $p<0.001$ level except for the joint-different and sole registered group on pre-term babies $(p<0.002)$.

Stillbirth rates were slightly above the national rate for both joint registered groups, which were the same. The stillbirth rate was highest in the sole registered group at 6.6 per 1,000 total births compared with a rate of 4.8 in the within-marriage group. The sole registered group differed significantly from all other registration group types $(p<0.001)$. The joint-same group differed from the within-marriage group $(p<0.01)$ but the joint-different group did not differ significantly from either the within-marriage group or the joint-same group. 
Neonatal mortality rates were higher for the joint-different (4.2 per 1,000 live births) and the sole registered group (3.7 per 1,000 live births). These groups did not differ significantly from each other but were both different from the within-marriage group $(p<0.001)$. The joint-same group differed from all other groups: the joint-different $(p, 0.001)$, the sole registered $(p<0.05)$ and the withinmarriage $(p<0.02)$.

These two non-resident father groups had similar infant mortality rates of 6.4 and 6.3 per 1,000 live births for the joint-different and sole registered respectively. Again, these groups did not differ significantly from each other but were both different from the within-marriage group and the jointsame group $(p<0.001)$. This compared with the much lower rates of 4.2 and 4.5 per 1,000 live births for the within-marriage and joint-same groups respectively. These two groups were also significantly different $(p=0.01)$.

Immaturity-related conditions were the most common cause of death group for all registration groups (Table 3). Congenital anomalies were also a highly represented group, especially in the within-marriage group. All other cause of death groups represented small proportions so group contrast should be made with caution. In this hierarchical classification, the proportion of deaths coded to Sudden Infant Death Syndrome (SIDS) was four times greater in the sole registered group than the within-marriage group.

\section{Table 3 Infant mortality by ONS cause groups and registration type, babies born in 2007-08}

\begin{tabular}{|c|c|c|c|c|c|}
\hline \multicolumn{5}{|l|}{ England and Wales } & \multirow[t]{2}{*}{ Per cent } \\
\hline \multirow[t]{3}{*}{ ONS Cause groups } & \multirow[t]{3}{*}{ All } & \multicolumn{3}{|c|}{ Marital status/type of registration } & \\
\hline & & \multirow[t]{2}{*}{ Inside marriage } & \multicolumn{2}{|c|}{ Joint registration } & Sole registration \\
\hline & & & same address & different address & \\
\hline Congenital anomalies & 29.5 & 35.7 & 24.8 & 20.6 & 22.1 \\
\hline Antepartum infection & 2.8 & 2.5 & 2.7 & 3.7 & 3.3 \\
\hline Immaturity related conditions & 44.6 & 42.3 & 47.2 & 49.4 & 42.2 \\
\hline $\begin{array}{l}\text { Asphyxia, anoxia or trauma } \\
\text { (intrapartum) }\end{array}$ & 7.0 & 7.8 & 7.3 & 5.1 & 4.5 \\
\hline External conditions & 1.5 & 1.0 & 1.4 & 2.6 & 3.5 \\
\hline Infections & 4.1 & 3.2 & 4.2 & 5.5 & 6.6 \\
\hline Other specific conditions & 1.2 & 1.3 & 1.3 & 0.9 & 1.1 \\
\hline Sudden infant deaths & 5.2 & 2.7 & 6.5 & 7.7 & 11.3 \\
\hline Other conditions & 4.2 & 3.6 & 4.7 & 4.6 & 5.4 \\
\hline
\end{tabular}

Source: ONS 
As low birthweight is a key indicator of a healthy pregnancy and the baby's healthy outcome, this was explored across registration groups after adjustment for prematurity, area deprivation, mother's age and ethnicity. As area deprivation was measured differently for England and Wales, these were analysed and reported separately (Tables $4 a$ and $4 b$ ). The adjusted odds ratios for individual explanatory variables and all combined are reported in Annex B. For England, prematurity and area deprivation were key explanatory variables. Ethnicity, here White versus nonwhite, was also an important explanatory variable; the more complex pattern of results with this may reflect a number of factors including its significant correlation with area deprivation. Inclusion of these explanatory variables explained between about 25 to 50 per cent of the variance in the group comparisons for England.

The analysis of the Wales data excluded mother's age as this was not significantly associated with low birthweight. Area deprivation was the key explanatory variable.

\section{Table 4a Unadjusted and adjusted odds ratios (OR) for low birthweight by registration group, singleton births ${ }^{1}$}

England

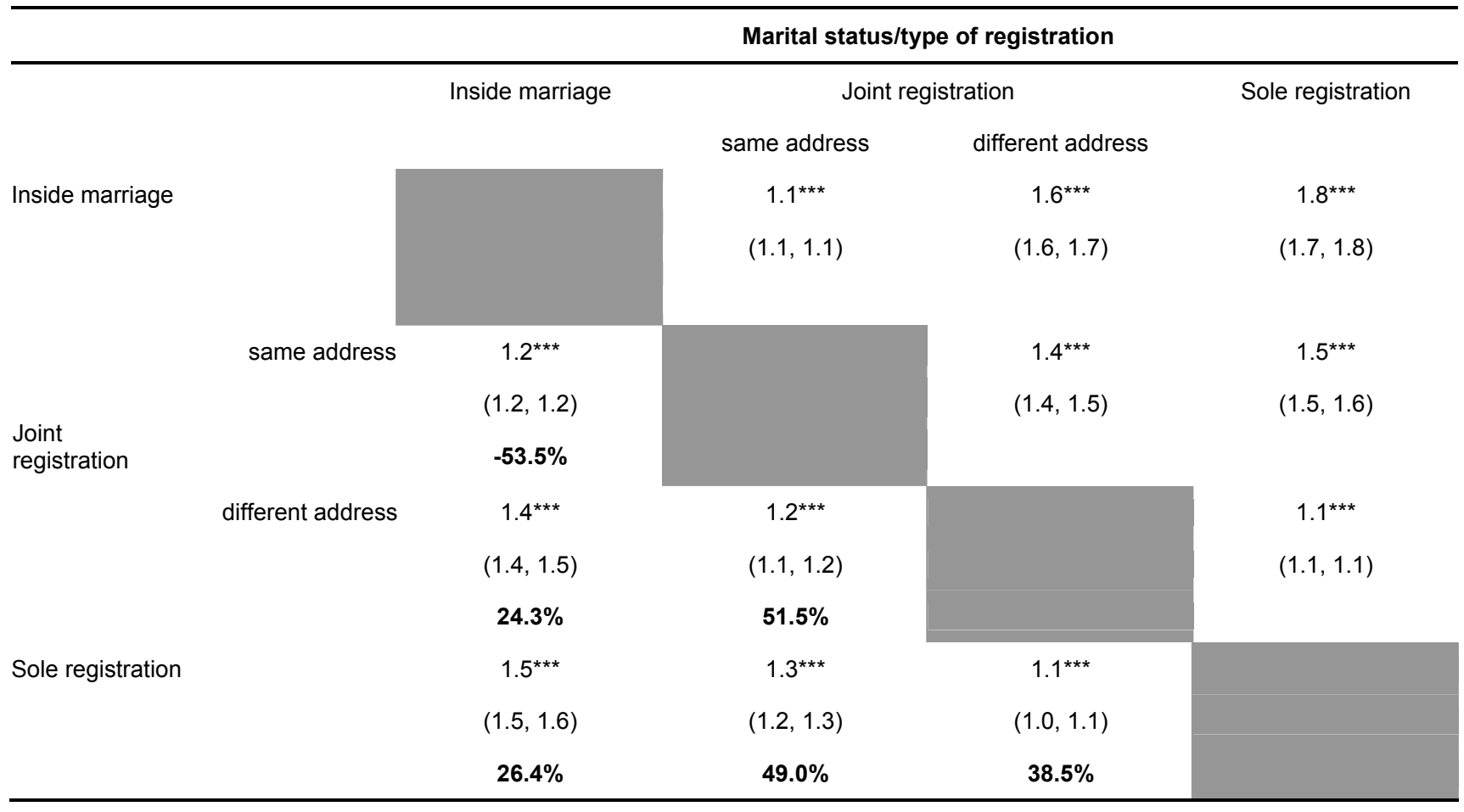

1 Singleton births in England with all variables present: $n=1,151,553$

Above the diagonal: Unadjusted odds ratios

Below the diagonal: Adjusted for prematurity, area deprivation, mother's young age at baby's birth, ethnicity (non-white)

Odds ratios, $95 \%$ confidence intervals in parentheses, percentage explained

${ }^{*} p \leq 0.05^{* *} p \leq 0.01{ }^{* * *} p \leq 0.001$

Source: ONS 


\section{Table 4b Unadjusted and adjusted odds ratios (OR) for low birthweight by registration group, singleton births ${ }^{1}$}

Wales

\begin{tabular}{|c|c|c|c|c|}
\hline & \multicolumn{4}{|c|}{ Marital status/type of registration } \\
\hline & \multirow[t]{2}{*}{ Inside marriage } & \multicolumn{2}{|c|}{ Joint registration } & Sole registration \\
\hline & & same address & different address & \\
\hline \multirow[t]{2}{*}{ Inside marriage } & & $1.3^{* * *}$ & $1.7^{* * *}$ & $1.7^{* * *}$ \\
\hline & & $(1.2,1.4)$ & $(1.5,1.9)$ & $(1.5,1.9)$ \\
\hline \multirow[b]{3}{*}{$\begin{array}{l}\text { Joint } \\
\text { registration }\end{array}$} & $1.4^{* \star *}$ & & $1.3^{* * *}$ & $1.3^{* \star *}$ \\
\hline & $(1.2,1.5)$ & & $(1.2,1.4)$ & $(1.2,1.5)$ \\
\hline & $-20.7 \%$ & & & \\
\hline \multirow[t]{3}{*}{ different address } & $1.7^{* * *}$ & $1.2^{\star * *}$ & & 1.0 \\
\hline & $(1.5,1.9)$ & $(1.1,1.4)$ & & $(0.9,1.2)$ \\
\hline & $3.5 \%$ & $26.4 \%$ & & \\
\hline \multirow[t]{3}{*}{ Sole registration } & $1.8^{* * *}$ & $1.3^{* * *}$ & & \\
\hline & $(1.5,2.0)$ & $(1.1,1.5)$ & & \\
\hline & $-5.2 \%$ & $8.6 \%$ & & \\
\hline
\end{tabular}

1 Singleton births in Wales with all variables present: $n=67,050$

Above the diagonal: Unadjusted odds ratios

Below the diagonal: Adjusted for prematurity, area deprivation, ethnicity (non-white)

Odds ratios, $95 \%$ confidence intervals in parentheses, percentage explained

${ }^{*} p \leq 0.05 \quad * * 0 \leq 0.01 \quad * * * 0 \leq 0.001$

Source: ONS

The joint-different and sole registered groups did not differ from each other in their rates of infant mortality. The other group differences in infant mortality were explored adjusted for key sociodemographic characteristics for England and Wales separately (Tables 5a and 5b). There were no significant registration group differences for infant deaths for the Wales data and so no further analysis was carried out. For the England data, as low birthweight and prematurity are so highly correlated, both were not included in the multivariate model: low birthweight showed the strongest association and therefore was included, so again only singleton births were analysed. Firstly, the analysis was adjusted for prematurity, low birthweight, area deprivation, young mothers and ethnicity individually (Annex C). Then the multivariate analysis included all explanatory variables except prematurity. This adjustment explained a high proportion of the variance in group differences, from about 50 to 75 per cent. Low birthweight was the key explanatory variable for group differences in infant mortality, with area deprivation and young motherhood also important factors.

Further details of the regression models whose results are given in Tables 4 and 5 are contained in Annex A. 


\section{Table 5a Unadjusted and adjusted odds ratios (OR) for infant mortality by registration group, singleton births}

England

\begin{tabular}{|c|c|c|c|c|}
\hline & \multicolumn{4}{|c|}{ Marital status/type of registration } \\
\hline & Inside marriage & Joint & ration & Sole registration \\
\hline & & same address & different address & \\
\hline \multirow[t]{2}{*}{ Inside marriage } & & 1.0 & $1.5^{\star * *}$ & $1.6^{\star \star \star}$ \\
\hline & & $(0.9,1.1)$ & $(1.4,1.7)$ & $(1.5,1.8)$ \\
\hline \multirow[b]{2}{*}{$\begin{array}{l}\text { Joint } \\
\text { registration }\end{array}$} & & & $1.6^{\star \star *}$ & $1.5^{\star \star *}$ \\
\hline & & & $(1.4,1.7)$ & $(1.3,1.6)$ \\
\hline \multirow[t]{3}{*}{ different address } & $1.1^{* *}$ & $1.1^{*}$ & & 1.1 \\
\hline & $(1.0,1.3)$ & $(1.0,1.2)$ & & $(0.9,1.2)$ \\
\hline & $69.5 \%$ & $71.5 \%$ & & \\
\hline \multirow[t]{3}{*}{ Sole registration } & $1.1^{\star \star *}$ & $1.1^{*}$ & & \\
\hline & $(1.0,1.3)$ & $(1.0,1.2)$ & & \\
\hline & $73.4 \%$ & $75.4 \%$ & & \\
\hline
\end{tabular}

Above the diagonal: Unadjusted odds ratios

Below the diagonal: Adjusted for low birthweight, area deprivation, mother's young age at baby's birth, ethnicity (non-white)

Odds ratios, $95 \%$ confidence intervals in parentheses, percentage explained

${ }^{*} p \leq 0.05^{* *} p \leq 0.01{ }^{* * *} p \leq 0.001$

Source: ONS 


\section{Table 5b Unadjusted and adjusted odds ratios (OR) for infant mortality by registration group, singleton births}

Wales

\begin{tabular}{|c|c|c|c|c|}
\hline & \multicolumn{4}{|c|}{ Marital status/type of registration } \\
\hline & \multirow[t]{2}{*}{ Inside marriage } & \multicolumn{2}{|c|}{ Joint registration } & Sole registration \\
\hline & & same address & different address & \\
\hline \multirow[t]{2}{*}{ Inside marriage } & & 1.2 & 1.3 & 1.4 \\
\hline & & $(0.9,1.5)$ & $(0.9,1.9)$ & $(0.9,2.2)$ \\
\hline \multicolumn{2}{|c|}{ same address } & & 1.1 & 1.2 \\
\hline \multicolumn{2}{|l|}{$\begin{array}{l}\text { Joint } \\
\text { registration }\end{array}$} & & $(0.8,1.7)$ & $(0.8,1.9)$ \\
\hline \multicolumn{3}{|c|}{ different address } & & 1.1 \\
\hline \multicolumn{5}{|l|}{ Sole registration } \\
\hline
\end{tabular}

Above the diagonal: Unadjusted odds ratios

Odds ratios, $95 \%$ confidence intervals in parentheses, percentage explained

${ }^{*} p \leq 0.05^{* *} p \leq 0.01{ }^{* \star *} p \leq 0.001$

Source: ONS

\section{Discussion}

The four marital status and registration type groups were found to differ in key socio-demographic characteristics and across the main health outcomes, and it was evident that the sole registered group was disadvantaged in these areas. The similarity between the sole registered group and the joint-different group is marked, and these two groups together, comprising less than one-fifth of all births, may be said to represent births to non-resident fathers. The main characteristics were young mothers living in deprived circumstances and with elevated risk of giving birth to babies prematurely and with low birthweight. These risks lead to a much higher infant mortality rate than babies born in the other registered groups. In particular, the stillbirth rate was much higher in the sole registered group.

The within-marriage and joint-same (or cohabitation) groups, comprising more than four-fifths of all births, may be said to correspond to births occurring in families where the father was resident. These two groups did show some differences, but were more similar to each other than to the other registration groups. The mothers were older and less likely to be living in deprived circumstances. These characteristics were associated with a reduced likelihood of giving birth to a low birthweight or premature baby. The benefits to the baby were evident in the low neonatal and infant mortality rates. 
Analysis of previous years of the linked NN4B data has shown that young mothers, non-white ethnicity, births outside marriage and with high deprivation are associated with increased risk for infant mortality (Oakley et al, 2009). This analysis has clarified the inside-outside marriage distinction and provided evidence for the usefulness of keeping the four registration types separate and considering the importance of resident and non-resident fathers. The importance of the 'strength' of the parents' relationship and the context of childbearing has been emphasised in recent reports from the Millennium Cohort Study (Kiernan and Smith, 2003).

Infant mortality remains an important measure of the health of a society (DH, 2010b). Overall, infant mortality rates have been declining year on year but there are still key health inequalities evident within England and Wales. As well as adding to existing work on the socio-economic gradients for health, especially infant mortality, this article has enhanced this work by including key health measures.

Gestational age or prematurity is a powerful predictor of early survival, relevant for stillbirths and babies in their first week of life (Wilcox and Skjœrven, 1992). Beyond this first week, birthweight remains a powerful predictor of survival beyond the first birthday (Wilcox and Skjœrven, 1992). Both measures have been included.

Analysis of death certificates as ONS cause of death groups confirmed that immaturity-related conditions are the main cause of infant death. While the data available from birth registration cannot show conclusively all the relevant factors for healthy outcome at birth, some important statistical associations of factors across these groups have been demonstrated here using the linked data.

Low birthweight has shown itself as a key independent determinant of infant mortality. Other factors also associated with infant mortality may have both a direct effect on the risk of death, or indirect links through the consequences of low birthweight. For example, area deprivation is associated with health behaviours such as smoking and drinking, which in turn impact on fetal development, which increase the likelihood of premature and low birthweight babies (Perry and Lumey, 2004). Findings reported from the Millennium Cohort Study have shown that smoking during pregnancy, maternal weight and engagement in antenatal care vary by ethnic group (Gray et al, 2009), and other studies have reported that women's obesity varies with age, educational level, income level and ethnic group (Higgins and Dale, 2010). Fertility rates have also been shown to vary by ethnic group and migration history, and across these by mother's age at birth and pattern of childbearing (Dubuc and Haskey, 2010).

It is evident that pathways are complex and inter-related: for example, ethnic group and engagement in antenatal care may be associated with area deprivation, which is one pathway impacting on the mother's health and ultimately the baby's healthy outcome. The association between young mothers and the registration type groups of sole registered and joint-different may reflect a lack of planning in terms of relationships and pregnancy.

Unplanned pregnancies are associated with poorer outcomes for mother and baby and they are more common in the sole registered group (Graham et al, 2007), although the two joint-registered groups were not differentiated here. Congenital anomalies were also a highly represented cause of death group, especially in the within-marriage group, in part explained by certain characteristics of 
the mothers, namely age and ethnicity. Congenital anomalies are generally more prevalent in babies born to older mothers and there was a greater proportion of older mothers in the withinmarriage group. Also, most Asian births were within-marriage and other reports on this dataset (Office for National Statistics, 2010b) have shown that congenital anomalies were highest in the Asian ethnic group.

\section{Limitations of the analysis}

This analysis has examined all births occurring in England and Wales in 2007 and 2008 and through linkage with other data sources has included variables not previously routinely available, such as ethnicity and gestational age. However, there was a limited range of possible factors relevant for understanding the characteristics of the registration groups and their health risks and outcomes. For example, there are no behavioural measures, such as whether the mothers smoked during pregnancy, a key determinant of low birthweight (Perry and Lumey, 2004). Other studies have shown high rates of smoking in the sole registered group (Graham et al, 2007).

Splitting England and Wales for analysis which included area deprivation showed different findings for the two countries. Further analysis is needed to establish whether the registration group differences and the explanatory variables do indeed show different patterns in Wales, or whether the much smaller numbers in Wales did not provide enough power to show the same patterns as England. Further analysis using more aggregated years of linked data for Wales may add clarification.

Ethnicity is an important factor but there is debate about classifying this social construct. It is generally self-determined but here we have the mother's report of the baby's ethnicity. Further, about 9 per cent of records did not have a stated ethnic group. Analysis is underway to determine the impact of missing ethnicity, although no marked differences were found across registration type groups. Further, we have used the broad ethnic group classification here and there may be key differences between the sub-groups. Birthweight varies by ethnic group and thus what may be considered 'normal' for one ethnic group may differ for another. Standard definitions for low birthweight and Small for Gestational Age were applied to all women and any variation by ethnic group was not taken into account.

Area deprivation measures were correlated with a number of the variables used in this analysis. Further analysis could use the separate deprivation domains, such as Income and Environment, to assess the association with deprivation. In particular, removing the Health domain from the Wales analysis would remove the correlation with low birthweight which is included in this domain.

\section{Conclusions}

The findings reported here have described the different birth registration groups highlighting their differences and similarities, with a particular emphasis on measures which are disadvantageous to babies and their survival. While there is clear evidence that the sole registered group is a disadvantaged group, they have been shown to be similar to the joint-different group, an equally disadvantaged group. This would argue that when combining the registration groups for demographic and health statistics a different distinction in terms of resident versus non-resident fathers would be more meaningful. 
The results of the logistic regression confirm the importance of a range of factors, most of them related to socioeconomic deprivation, for premature birth, low birthweight and infant mortality. While the relationships between these influences are complex, there is strong evidence for the role of low birthweight as a common pathway in their effect on infant mortality. 


\section{References}

Berthoud R, McKay S and Rowlingson K (2004) Becoming a single mother. In S. McRae, ed. Changing Britain: Families and Households in the 1990s. Oxford: Oxford University Press. Ch. 15.

Collingwood Bakeo, A (2004) 'Trends in live births by mother's country of birth and other factors affecting low birthweight in England and Wales, 1983-2001', Health Statistics Quarterly, 23, 2533. Available on the ONS website at: www.statistics.gov.uk/hsq/

Communities and Local Government (2007) The English Indices of Deprivation 2007: Summary, Available on the Communities and Local Government website at: www.imd.communities.gov.uk/

Dattani N. and Rowan S. (2002) 'Causes of neonatal deaths and stillbirths: a new hierarchical classification in ICD-10', Health Statistics Quarterly 15 16-22. Available on the ONS website at: www.statistics.gov.uk/hsq/

Department for Work and Pensions (2008) Joint birth registration: recording responsibility, Available on the Department for Work and Pensions website at: www.dwp.gov.uk/publications/

Department of Health (2010a) Healthy Lives, Healthy People: Our strategy for public health in England, Available on Department of Health website at: www.dh.gov.uk/publications

Department of Health (2010b) Tackling health inequalities in infant and maternal health outcomes: report of the infant mortality national support team, Available on Department of Health website at: www.dh.gov.uk/publications

Dibben C, Sigala M and Macfarlane A (2006) Area deprivation, individual factors and low birth weight in England: is there evidence of an "area effect"? Journal of Epidemiology and Community Health, 60, 1053-1059.

Dubuc S and Haskey J (2010) Ethnicity and Fertility in the United Kingdom. In J. Stillwell and M. van Ham, eds. Ethnicity and Integration: Understanding Population Trends and Processes Vol. 3. Springer: Dordrecht. Ch.4.

Gartner A, Farewell D, Dunstan F and Gordon E (2008) 'Differences in mortality between rural and urban areas in England and Wales, 2002-04', Health Statistics Quarterly, 39, 6-13. Available on the ONS website at: www.statistics.gov.uk/hsq/

Graham J, Creegan C, Barnard M, Mowlam A and McKay S (2007) Sole and joint birth registration: exploring the circumstances, choices and motivations of unmarried parents. Research Report No. 463. Available on the Department for Work and Pensions website at: www.dwp.gov.uk/publications/

Gray R, Headley J, Oakley L, Kurinczuk J, Brocklehurst P and Hollowell J (2009) Towards an understanding of variations in infant mortality rates between different ethnic groups in England and Wales, Inequalities in Infant Mortality Project briefing Paper 3, National Perinatal Epidemiology Unit. Available on their website at: www.npeu.ox.ac.uk/ 
Haskey J (1999) 'Having a birth outside marriage: the proportions of lone mothers and cohabiting mothers who subsequently marry', Population Trends, 97, 6-18.

Higgins V and Dale A (2010) Ethnic differences in Physical activity and Obesity. In J. Stillwell and M. van Ham, eds. Ethnicity and Integration: Understanding Population Trends and Processes Vol. 3. Springer: Dordrecht. Ch.10.

Hilder L, Moser K, Dattani N and Macfarlane A (2007) 'Pilot linkage of NHS Numbers for Babies data with birth registrations', Health Statistics Quarterly, 33, 25-33. Available on the ONS website at: www.statistics.gov.uk/hsq/

Kiernan K and Smith K (2003) 'Unmarried parenthood: new insights from the Millennium Cohort Study', Population Trends, 114, 26-33.

Kuh D and Ben-Shlomo Y (2004) Introduction. In D. Kuh and Y. Ben-Shlomo, eds. A life course approach to chronic disease epidemiology2nd edition Oxford University Press: Oxford. Ch.1.

Lawlor DA, Ben-Shlomo Y and Leon DA (2004) Pre-adult influences on cardiovascular disease. In D. Kuh and Y. Ben-Shlomo, eds.A life course approach to chronic disease epidemiology2nd edition Oxford University Press: Oxford. Ch.3.

Moffitt TE, Caspi A, Belsky J and Silva PA (1992) 'Childhood experience and the onset of menarche' Child Development, 63, 47-58.

Oakley L, Maconochie N, Doyle P, Dattani N and Moser K (2009) 'Multivariate analysis of infant deaths in England and Wales in 2005-06, with a focus on socio-economic status and deprivation', Health Statistics Quarterly, 42, 23-39. Available on the ONS website at: www.statistics.gov.uk/hsq/

Office for National Statistics, Series DH3 (2010) Births and child mortality statistics. Available on the ONS website at: www.statistics.gov.uk/StatBase/Product.asp?vlnk=15362

Office for National Statistics (2010a) 'Social Trends Chapter 2: Households and families. Social Trends, 42, 13-26. Available on the ONS website at: www.statistics.gov.uk/socialtrends/

Office for National Statistics (2010b) 'Gestation-specific infant mortality in England and Wales, 2007-08'. Available on the ONS website at:

www.statistics.gov.uk/StatBase/Product.asp?vlnk=15309

Perry IJ and Lumey LH (2004) Fetal growth and development: the role of nutrition and other factors. In D. Kuh and Y. Ben-Shlomo, eds.A life course approach to chronic disease epidemiology2nd edition Oxford University Press: Oxford. Ch.15.

Shouls S, Whitehead M, Burström B and Diderichsen F (1999) 'The health and socio-economic circumstances of British lone mothers over the last two decades' Population Trends, 95, pp.41-46.

Smallwood S (2004) 'Characteristics of sole registered births and the mothers who register them' Population Trends, 117, 20-26.

StataCorp (2007) Stata Statistical Software: Release 9.2 College Station, TX: StataCorp LP. 
Strachan DP and Sheikh A (2004) A life course approach to respiratory and allergic diseases. In D. Kuh and Y. Ben-Shlomo, eds.A life course approach to chronic disease epidemiology2nd edition Oxford University Press: Oxford. Ch.10.

Wellings K and Wadsworth J (2004) Family influences on teenage fertility. In S. McRae, ed.

Changing Britain: Families and Households in the 1990s. Oxford: Oxford University Press. Ch. 13.

Welsh Assembly Government (2008) Welsh Index of Multiple Deprivation (2008) Summary Report. Available on the Welsh Assembly Government website at: www.wales.gov.uk/topics/statistics/theme/wimd/?lang=en

Wigglesworth, J.S. (1980) 'Monitoring perinatal mortality. A pathophysiological approach', Lancet 2 pp 684-86.

Wilcox AJ and Skjœrven R (1992) 'Birth weight and perinatal mortality: the effect of gestational age', American Journal of Public Health, 82, 378-382.

World Health Organisation (1977) Manual of the international statistical classification of diseases, injuries, and causes of death, Volume 1. World Health Organization: Geneva. 
Annex A

\section{Table A1a Variables included in the analyses for low birthweight}

\begin{tabular}{lrr}
\hline Variable & Classification & Stage of Modelling \\
\hline Outcome variable: low birthweight & Birthweight less than 2,500g & - \\
Prematurity & Less than 37 weeks completed gestation & 1 \\
Deprivation & Most deprived quintile & 2 \\
Mother's age at baby's birth & Under 20 years & 3 \\
Ethnicity & Non-white & 4 \\
\hline
\end{tabular}

Source: ONS

\section{Table A1b Variables included in the analyses for infant death}

\begin{tabular}{lcr}
\hline Variable & Classification & Stage of Modelling \\
\hline Outcome variable: infant death & Baby died before first birthday & - \\
Prematurity & Less than 37 weeks completed gestation & (excluded) \\
Low birthweight & Birthweight less than 2,500g & 1 \\
Deprivation & Most deprived quintile & 2 \\
Mother's age at baby's birth & Under 20 years & 3 \\
Ethnicity & Non-white & 4 \\
\hline
\end{tabular}

Source: ONS 


\section{Annex B}

\section{Table B1 Unadjusted and adjusted odds ratios (OR) for low birthweight by registration group, singleton births}

England

\begin{tabular}{|c|c|c|c|c|c|c|}
\hline & \multicolumn{6}{|c|}{ Marital status/type of registration } \\
\hline & \multicolumn{2}{|c|}{ Inside marriage vs } & & \multirow{2}{*}{$\begin{array}{l}\text { Joint same } \\
\text { Joint different }\end{array}$} & \multicolumn{2}{|c|}{ Sole registered } \\
\hline & Joint same & Joint different & Sole registered & & Joint same & Joint different \\
\hline \multirow[t]{2}{*}{ Unadjusted } & $1.1^{* \star *}$ & $1.6^{\star \star \star}$ & $1.8^{* \star *}$ & $1.4^{* * *}$ & $1.5^{\star \star \star}$ & $1.1^{* \star \star}$ \\
\hline & $(1.1,1.1)$ & $(1.6,1.7)$ & $(1.7,1.8)$ & $(1.4,1.5)$ & $(1.5,1.6)$ & $(1.1,1.1)$ \\
\hline \multirow[t]{3}{*}{ Prematurity } & $1.1^{\star \star \star}$ & $1.5^{\star \star \star}$ & $1.6^{* \star *}$ & $1.3^{\star \star *}$ & $1.5^{\star \star \star}$ & $1.1^{\star \star *}$ \\
\hline & $(1.1,1.1)$ & $(1.4,1.5)$ & $(1.5,1.7)$ & $(1.3,1.4)$ & $(1.4,1.5)$ & $(1.0,1.1)$ \\
\hline & $33.1 \%$ & $20.5 \%$ & $17.9 \%$ & $16.0 \%$ & $13.6 \%$ & $3.5 \%$ \\
\hline \multirow[t]{3}{*}{ Area deprivation } & $1.1^{* \star *}$ & $1.5^{\star * *}$ & $1.6^{\star * *}$ & $1.3^{* * *}$ & $1.5^{\star * *}$ & $1.1^{* \star *}$ \\
\hline & $(1.1,1.1)$ & $(1.4,1.5)$ & $(1.6,1.7)$ & $(1.3,1.4)$ & $(1.4,1.5)$ & $(1.0,1.1)$ \\
\hline & $19.1 \%$ & $17.9 \%$ & $16.5 \%$ & $17.4 \%$ & $15.7 \%$ & $8.4 \%$ \\
\hline \multirow[t]{3}{*}{ Mum aged under 20 years } & $1.1^{* * *}$ & $1.6^{\star \star *}$ & $1.7^{* * *}$ & $1.4^{* * *}$ & $1.5^{\star * *}$ & $1.1^{* * *}$ \\
\hline & $(1.1,1.1)$ & $(1.5,1.6)$ & $(1.7,1.8)$ & $(1.4,1.4)$ & $(1.5,1.6)$ & $(1.1,1.1)$ \\
\hline & $7.5 \%$ & $6.8 \%$ & $4.4 \%$ & $5.1 \%$ & $3.5 \%$ & $-3.1 \%$ \\
\hline \multirow[t]{3}{*}{ Ethnicity (non-white) } & $1.3^{* * *}$ & $1.7^{* * *}$ & $1.8^{* * *}$ & $1.3^{\star * *}$ & $1.4^{* * *}$ & $1.1^{* * *}$ \\
\hline & $(1.3,1.3)$ & $(1.7,1.8)$ & $(1.8,1.9)$ & $(1.3,1.4)$ & $(1.4,1.5)$ & $(1.0,1.1)$ \\
\hline & $-97.7 \%$ & $-12.0 \%$ & $-5.8 \%$ & $18.0 \%$ & $20.3 \%$ & $29.7 \%$ \\
\hline \multirow[t]{3}{*}{ All explanatory variables } & $1.2^{\star \star \star}$ & $1.4^{\star \star *}$ & $1.5^{\star \star *}$ & $1.2^{* * *}$ & $1.3^{* * *}$ & $1.1^{*}$ \\
\hline & $(1.2,1.2)$ & $(1.4,1.5)$ & $(1.5,1.6)$ & $(1.1,1.2)$ & $(1.2,1.3)$ & $(1.0,1.1)$ \\
\hline & $-53.5 \%$ & $24.3 \%$ & $26.4 \%$ & $51.5 \%$ & $49.0 \%$ & $38.5 \%$ \\
\hline
\end{tabular}

Odds ratios, $95 \%$ confidence intervals in parentheses, percentage explained

${ }^{*} p \leq 0.0{ }^{* *} p \leq 0.01{ }^{* * *} p \leq 0.001$

Source: ONS 
Annex B

\section{Table B2 Unadjusted and adjusted odds ratios (OR) for low birthweight by registration group, singleton births}

Wales

\begin{tabular}{|c|c|c|c|c|c|c|}
\hline & \multicolumn{6}{|c|}{ Marital status/type of registration } \\
\hline & \multicolumn{2}{|c|}{ Inside marriage vs } & & \multirow{2}{*}{$\begin{array}{l}\text { Joint same } \\
\text { Joint different }\end{array}$} & \multicolumn{2}{|c|}{ Sole registered } \\
\hline & Joint same & Joint different & Sole registered & & Joint same & Joint different \\
\hline \multirow[t]{2}{*}{ Unadjusted } & $1.3^{* * *}$ & $1.7^{* * *}$ & $1.7^{* \star *}$ & $1.3^{* * *}$ & $1.3^{* * *}$ & 1.0 \\
\hline & $(1.2,1.4)$ & $(1.5,1.9)$ & $(1.5,1.9)$ & $(1.2,1.4)$ & $(1.2,1.5)$ & $(0.9,1.2)$ \\
\hline \multirow[t]{3}{*}{ Prematurity } & $1.3^{\star \star \star}$ & $1.7^{* \star *}$ & $1.8^{* * *}$ & $1.3^{* * *}$ & $1.4^{* * *}$ & \\
\hline & $(1.2,1.4)$ & $(1.5,1.9)$ & $(1.6,2.1)$ & $(1.1,1.4)$ & $(1.2,1.6)$ & \\
\hline & $-6.3 \%$ & $1.7 \%$ & $-10.8 \%$ & $9.3 \%$ & $-14.9 \%$ & \\
\hline \multirow[t]{3}{*}{ Area deprivation } & $1.3^{\star \star \star}$ & $1.5^{\star * *}$ & $1.6^{* * *}$ & $1.2^{* \star *}$ & $1.3^{* * *}$ & \\
\hline & $(1.2,1.3)$ & $(1.4,1.7)$ & $(1.4,1.8)$ & $(1.1,1.4)$ & $(1.1,1.4)$ & \\
\hline & $13.3 \%$ & $14.9 \%$ & $13.9 \%$ & $16.4 \%$ & $14.5 \%$ & \\
\hline \multirow[t]{3}{*}{ Ethnicity (non-white) } & $1.4^{\star \star \star}$ & $1.7^{\star \star \star}$ & $1.7^{* \star \star}$ & $1.3^{* * *}$ & $1.3^{* \star *}$ & \\
\hline & $(1.3,1.5)$ & $(1.6,1.9)$ & $(1.6,2.0)$ & $(1.2,1.4)$ & $(1.1,1.5)$ & \\
\hline & $-19.9 \%$ & $-8.7 \%$ & $-5.2 \%$ & $2.0 \%$ & $8.0 \%$ & \\
\hline \multirow[t]{3}{*}{ All explanatory variables } & $1.4^{\star * *}$ & $1.7^{\star \star *}$ & $1.8^{* * *}$ & $1.2^{* \star *}$ & $1.3^{* * *}$ & \\
\hline & $(1.2,1.5)$ & $(1.5,1.9)$ & $(1.5,2.0)$ & $(1.1,1.4)$ & $(1.1,1.5)$ & \\
\hline & $-20.7 \%$ & $3.5 \%$ & $-5.2 \%$ & $26.4 \%$ & $8.6 \%$ & \\
\hline
\end{tabular}

Odds ratios, $95 \%$ confidence intervals in parentheses, percentage explained

${ }^{*} p \leq 0.05^{* *} p \leq 0.01{ }^{* * *} p \leq 0.001$

Source: ONS 
Annex C

Table C1 Unadjusted and adjusted odds ratios (OR) for infant deaths by registration group, singleton births

England

\begin{tabular}{|c|c|c|c|c|c|}
\hline \multicolumn{6}{|c|}{ Marital status/type of registration } \\
\hline & \multicolumn{2}{|c|}{ Inside marriage vs } & \multirow{2}{*}{$\begin{array}{l}\text { Joint same } \\
\text { Joint different }\end{array}$} & \multicolumn{2}{|c|}{ Sole registered } \\
\hline Joint same & Joint different & Sole registered & & Joint same & Joint different \\
\hline \multirow[t]{2}{*}{ Unadjusted } & $1.5^{\star * \star}$ & $1.6^{\star \star *}$ & $1.6^{* \star *}$ & $1.5^{\star \star *}$ & 1.1 \\
\hline & $(1.4,1.7)$ & $(1.5,1.8)$ & $(1.4,1.7)$ & $(1.3,1.6)$ & $(0.9,1.2)$ \\
\hline \multirow[t]{3}{*}{ Prematurity } & $1.3^{* * *}$ & $1.3^{* \star *}$ & $1.3^{* * *}$ & $1.3^{* * *}$ & \\
\hline & $(1.2,1.4)$ & $(1.2,1.4)$ & $(1.2,1.4)$ & $(1.2,1.5)$ & \\
\hline & $44.7 \%$ & $46.0 \%$ & $33.9 \%$ & $36.6 \%$ & \\
\hline \multirow[t]{3}{*}{ Low birthweight ${ }^{\dagger}$} & $1.2^{* * *}$ & $1.2^{* * *}$ & $1.2^{* * *}$ & $1.2^{* * *}$ & \\
\hline & $(1.1,1.3)$ & $(1.1,1.3)$ & $(1.1,1.4)$ & $(1.1,1.4)$ & \\
\hline & $57.6 \%$ & $61.5 \%$ & $46.9 \%$ & $52.3 \%$ & \\
\hline \multirow[t]{3}{*}{ Area deprivation ${ }^{\dagger}$} & $1.4^{\star \star \star}$ & $1.4^{* * *}$ & $1.4^{\star * *}$ & $1.4^{* * *}$ & \\
\hline & $(1.3,1.5)$ & $(1.3,1.6)$ & $(1.3,1.5)$ & $(1.3,1.6)$ & \\
\hline & $25.0 \%$ & $24.1 \%$ & $19.5 \%$ & $19.2 \%$ & \\
\hline \multirow[t]{3}{*}{ Mum aged under 20 years ${ }^{\dagger}$} & $1.4^{* \star *}$ & $1.5^{\star \star *}$ & $1.4^{\star \star \star}$ & $1.5^{\star \star \star *}$ & \\
\hline & $(1.3,1.6)$ & $(1.4,1.7)$ & $(1.3,1.6)$ & $(1.4,1.7)$ & \\
\hline & $19.0 \%$ & $15.4 \%$ & $13.5 \%$ & $10.3 \%$ & \\
\hline \multirow[t]{3}{*}{ Ethnicity (non-white) ${ }^{\dagger}$} & $1.6^{\star * \star}$ & $1.7^{\star \star \star}$ & $1.4^{\star \star *}$ & $1.4^{* \star *}$ & \\
\hline & $(1.5,1.8)$ & $(1.5,1.9)$ & $(1.3,1.5)$ & $(1.3,1.6)$ & \\
\hline & $-14.5 \%$ & $-7.1 \%$ & $18.4 \%$ & $22.6 \%$ & \\
\hline \multirow[t]{3}{*}{ Four explanatory variables marked ${ }^{\dagger}$} & $1.1^{* *}$ & $1.1^{* * *}$ & $1.1^{*}$ & $1.1^{*}$ & \\
\hline & $(1.0,1.3)$ & $(1.0,1.3)$ & $(1.0,1.2)$ & $(1.0,1.2)$ & \\
\hline & $69.5 \%$ & $73.4 \%$ & $71.5 \%$ & $75.4 \%$ & \\
\hline
\end{tabular}

Odds ratios, $95 \%$ confidence intervals in parentheses, percentage explained

${ }^{*} p \leq 0.05{ }^{* *} p \leq 0.01{ }^{* * *} p \leq 0.001$

Source: ONS 